\title{
Research on the Giant and Complex Financial Information System Engineering Management from the Perspective of Meta-synthesis Methodology — with the Bank Card Informa- tion Exchange System Engineering as a Sample
}

\begin{abstract}
The paper empirically studies the engineering practices of the national currency circulation information system-China Union Pay's Bankcard Information Exchange System. By integrating the meta-synthesis methodology and the financial information system engineering, the paper proposes basic principles and processes of the giant and complex financial information system engineering management, and further explores its paradigm and toolkit.
\end{abstract}

Keywords: financial information system, meta-synthesis methodology, bank card, information exchange

\section{Introduction}

Modern payment industry is the foundation of financial modernization, and the bankcard industry is the major driving force for advancing the payment industry into the digital era. The payment industry plays a major role in promoting socio-economic development. First, it facilitates daily life and drives consumption. International experience shows that GDP grows by 0.5 to 0.8 percent with every 10 percent increase in the ratio of bank card payments. Secondly, it expands the tax base which leads to an increase in revenue. Thirdly, it enhances the efficiency of capital operation and thus reduces social costs.

As the primary part of the infrastructure in China's bank card industry, China Union Pay's bankcard information

Manuscript received May 15, 2016; accepted August 7, 2016

Hong-feng Chai

China UnionPay Co. Ltd, Shanghai 200135, China

Quan Sun $(\bowtie)$

National Engineering Laboratory for Electronic Commerce and Electronic Payment, Shanghai 201201, China

Email: quansun@unionpay.com exchange system engineering represents the national currency circulation information engineering as well as one of the core of the first four projects of China's informatization construction. It is the giant network engineering for the bankcard cross-bank information exchange that realized the interoperability of bankcard network for the first time. The large-scale system connects thousands of institutions and tens of millions of merchants nationwide and worldwide and provides service for billions of cardholders. It demonstrates typical properties of the giant and complex engineering. The implementation of the engineering has facilitated the rapid development of China's bankcard industry and lays foundation for the sustained and rapid growth of China's bankcard market (Figure 1).

\section{Basic principles for the giant and complex financial information system engineering management}

As a dynamic meta-synthesis process, the giant and complex financial information system engineering management should follow a set of basic principles, namely, the holistic principle, the development principle and the hierarchy principle.

\subsection{Holistic principle}

The giant and complex system should be considered as a whole. Since all factors within the system are interdependent and mutually restraining, various factors within the system should be well coordinated in the decisionmaking process in order to strike a holistic balance so that the whole is greater in its effect than the parts aggregated.

In the practice of the bankcard information exchange system engineering, it takes the system and the industrial chain environment as an organic whole, and coordinates 


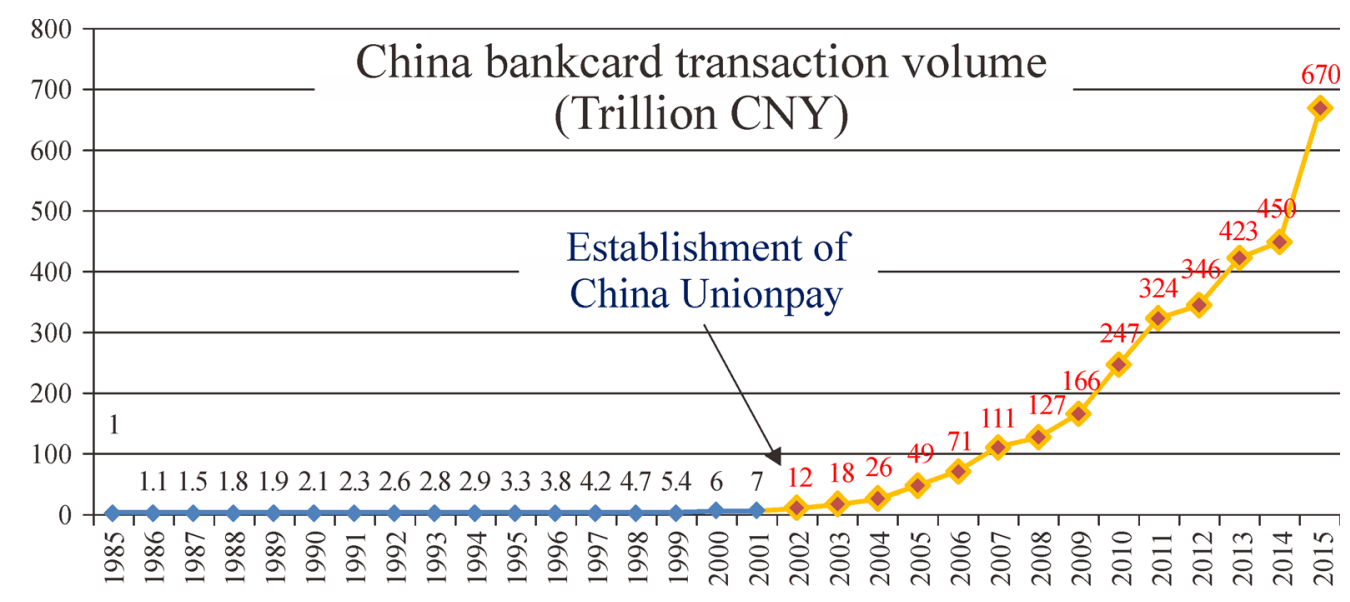

Figure 1. Trend of China bank card transaction volume increase.

the industrial chain to achieve overall balance, including performance and function, security and efficiency, revenue and cost, concurrent processing capability and response time.

\subsection{Development principle}

As the system evolves, the environment and ways of interaction between the internal and external change, the system remains dynamic. It has to undergo enhancements in order to adapt to the environment. The system development is divided into phases, normally, the change emerges gradually.

During the practice of the bankcard information exchange system engineering, substantial growth of the volume of cards and terminals as well as transaction amount annually constitutes internal factors, technical guidance and market impetus composes external factors. The two sets of factors combine to raise the needs of cultivating the proactivity and adaptability to stand up to the changes in the complex environment. According to market requirements and the engineering practice, it is decided that the construction should be divided into three phases, namely, Centralized Switching, Unified Clearing and Settlement, and Model Platform.

\subsection{Hierarchy principle}

A largely complex system often presents a distinct hierarchical property. Engineering management seizes principal problems and primary aspects and applies corresponding methodologies to problems on different levels. The application should be neither absent nor misplaced.

In the practice of the bankcard information exchange system engineering, each section on the industrial chain, the hierarchy and distribution of sub-systems, urgency and priority, domestic and global market, the transaction amount at each node, as well as primary and minor tasks at each phase should be identified clearly.

\section{Basic process of the giant and complex financial information system engineering management}

The giant and complex financial information system engineering management achieves an integration of the meta-synthesis methodology and financial information system engineering (Qian, Yu, \& Dai, 1990). By integrating the expert structure, machinery system and knowledge system under the guidance of people-centered and humanmachine integration, it identifies problems and objectives, conducts the qualitative and quantitative analysis, metasynthesis and finally reaches a quantitative conclusion. Furthermore, by continuous iteration and enhancement, it transforms the original system to the targeted system and will ultimately achieve the engineering goal (Wang, 2015) (Figure 2).

\subsection{Recognizing problems}

In 2002, through the implementation of the Golden Card project, a national strategy, regional bankcard network service centers were set up in 18 major cities, based on which a national center was built. However, China's bankcard industry is challenged by scattered networks, version conflicts, non-standard practice of technical standards and business rules, market chaos caused by interbank, cross-region and cross-country bankcard usages, low success rate, which is demonstrated as below: First, transaction amount is low. In 2001, the national center processed a total amount of 2,980,000 transactions with an amount of 352 million CNY. Secondly, proportion is low. Bankcard penetration rate stands only at $2.7 \%$, which means only $2.7 \mathrm{CNY}$ in every $100 \mathrm{CNY}$ consumption was 


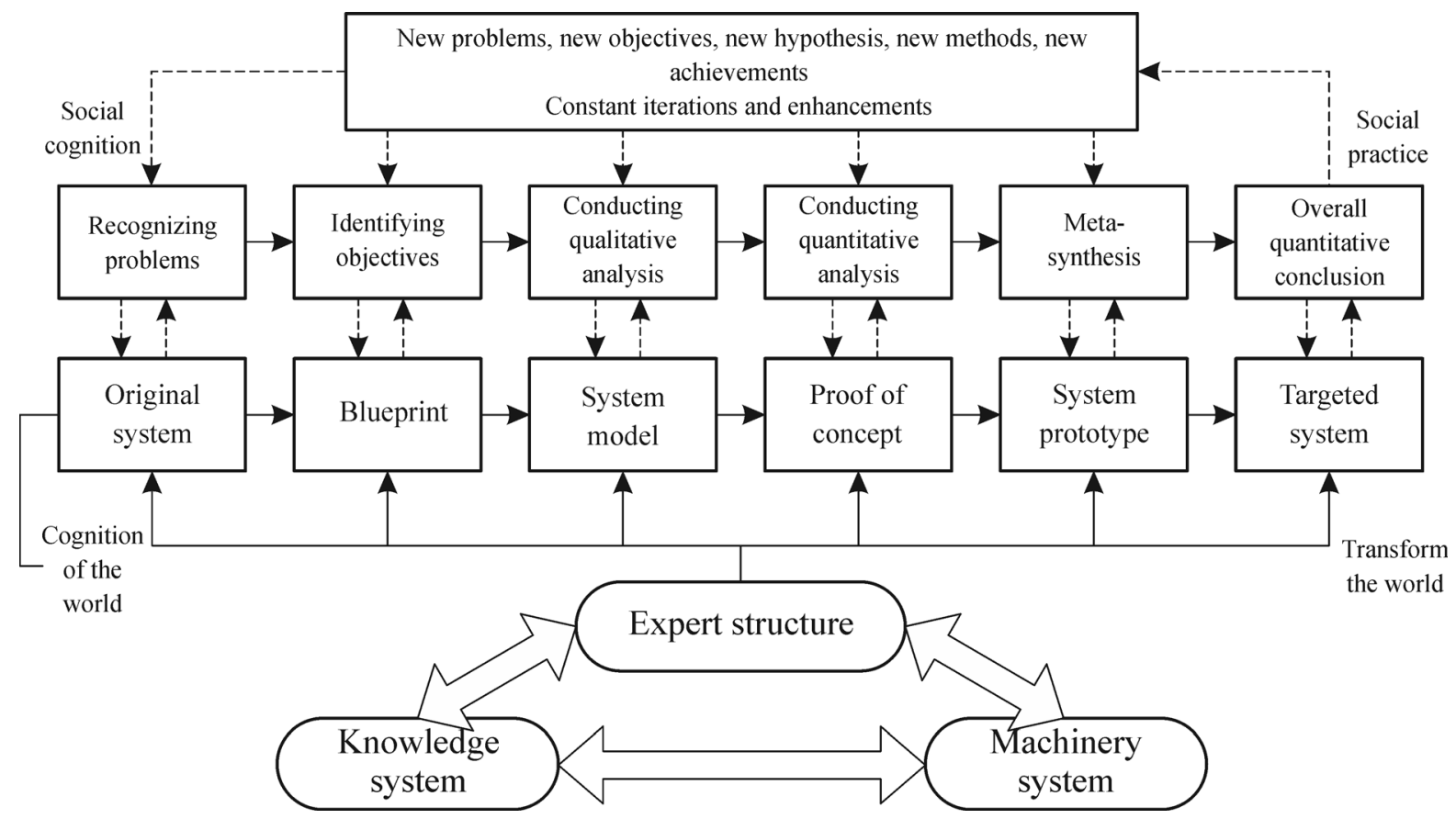

Figure 2. Basic process of the giant and complex financial information system engineering management.

paid with bank card. Thirdly, transaction quality is low. The success rate of cross-bank transaction was only $48 \%$. Fourthly, acceptance environment is unsatisfactory. There were only 185,000 merchants with a total of 270,000 POS terminals nationwide. Urgent needs emerged calling for establishing a modern bankcard system to meet the requirements of economic development and social services.

This is a large-scale engineering with the objective to connect thousands of institutions, tens of millions of merchants and provide service to billions of cardholders. Requirements include various design specifications, complicated functions, high level of real-time performance, reliability and security, around the clock uninterrupted business operation, real time capability for transaction processing. The peak-level processing capability should be able to meet the situation where cardholders worldwide are conducting transactions simultaneously as well as mass concurrence and leapfrog transaction requirements. The system provides multiple interfaces that are compatible with full range of business functions of banks and other institutions. Other challenges are listed below. Technologies are wide in scope with great time span. Making advances as a whole and under full alignment are difficult. Quality control is difficult. Meanwhile, the system has to meet requirements to be put forth by future consumption.

\subsection{Identifying objectives}

Based on problems analysis and experts' decision, the engineering blueprint is devised and objectives are identified as the following: First, to realize centralized processing of bankcard cross-bank information exchange, creating a bankcard cross-bank information exchange platform with wide regional coverage, comprehensive business types and powerful processing capability. Secondly, to establish and promote a bankcard interoperability technical specifications system, achieving both domestic and global bankcard acceptance. Thirdly, to construct China's own bankcard brand and cultivate the core competitiveness for China's bank card industry. In November 2001, UnionPay Preparation Group approved the Proposal for the Construction Plan of China UnionPay New System, officially launching the program of the construction of the bankcard information exchange system.

\subsection{Conducting qualitative analysis}

Based on the consolidation of information related to the financial information system from China and around the world, and through plenty of experts' discussion, meanwhile drawing on the empirical observation and instinct of experts and participants, China Union Pay preliminarily determined the system model of this complicated system, which is a centralized processing system including online system and background system.

The online system is extremely attentive to the processing performance and efficiency, making sure that the system is able to process bankcard transactions for billions of global cardholders in real time. The background system is the batch processing system that handles clearing 
and manages various complex functions. The whole system and each sub-system are proactive and adaptable to changes in the complex environment. They are flexible to extend both horizontally and vertically. In November, 2002, Union Pay complete the General Design Document and established the bankcard information exchange system framework model (Figure 3).

\subsection{Conducting quantitative analysis}

The Proof of Concept of the system model relies on the massive and complicated computer system. The system simulates, experiments, computes and conducts qualitative analysis of the model. Key qualitative POC validations include the following:

\subsubsection{System framework validation}

Traditionally, critical applications of the financial system were built on the proprietary host. In contrast, it is unprecedented to build a national centralized system with critical applications on an open platform. Hence the engineering is posed with tremendous technical challenges.

\subsubsection{High performance simulation and validation}

Online transactions are processed in a distributed and parallel manner. The system is designed to allow multiple parallel processing, multi-layer and multi-group framework, and multi-level dynamic load balancing mechanism. The system is able to handle 10,000 bankcard transactions per second at peak time.

\subsubsection{High availability simulation and validation}

The system is built on the foundation of self-adaptive flow distribution technology. The design of seamless rolling upgrade technology realizes $24 * 7$ non-stop stable running so that system upgrades and maintenance do not entail system halt any longer.

\subsubsection{Transactional mode simulation and validation}

By arranging and combining total factors of payment information, the result of the simulation and validation proposes the single message transaction mode which complies with business rules of electronic currency (single message transaction refers to the processing of transactions where a digital payment is processed with one online message). The single message system achieves neat and efficient authorization, clearing and settlement.

\subsubsection{High reliability simulation and validation}

The system has proposed and built a disaster tolerant system with three back up centers in two cities. Local and remote disaster recovery validates the system's ability to process transactions and recover data under extreme conditions.

\subsection{Meta-synthesis}

Based on the qualitative analysis model and through quantitative validation combined with expertise and data information, a system prototype of the giant and complex financial information system is created. The system prototype integrates all major sub-systems and realizes basic functions of the giant and complex financial information system.

Meta-synthesis should be carried out step by step. To begin with, to conduct quantitative validation on the subsystem level and construct sub-system prototype. The second step is to synthesize the prototypes of two or more sub-systems in order to realize one or more functions of the giant and complex financial information system. And the last is to complete the synthesis of all sub-systems to realize

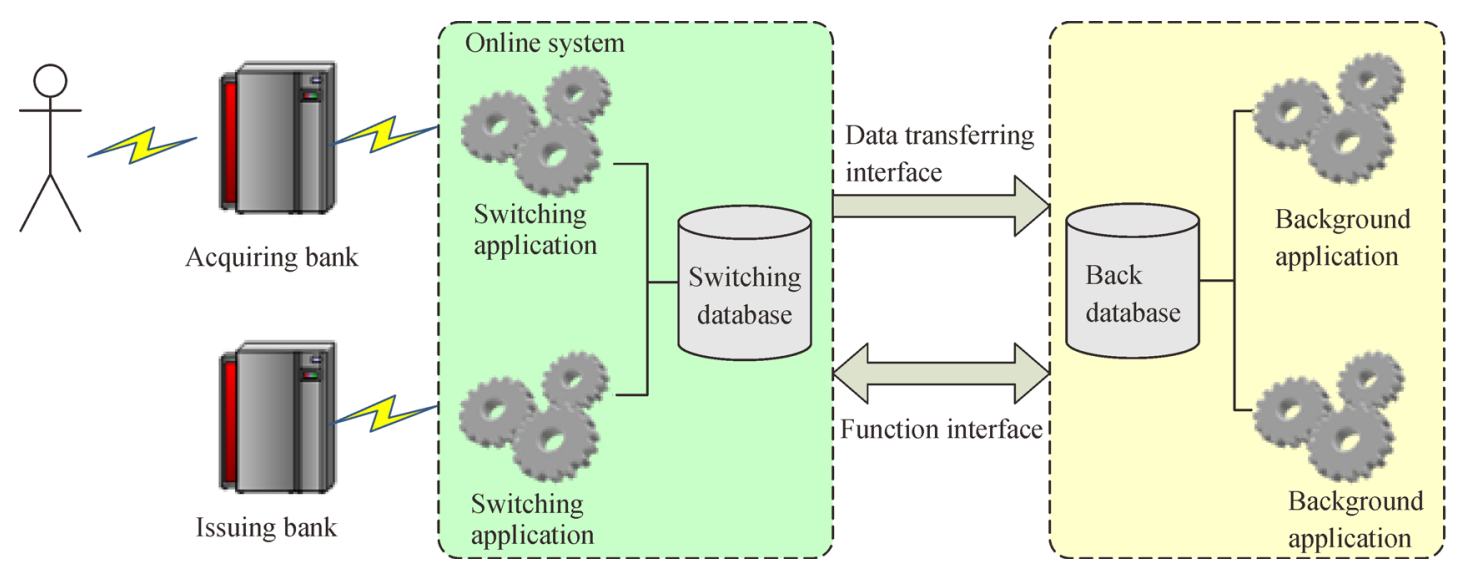

Figure 3. Bank card information exchange system framework model. 
the entire range of functions of the information system.

Through the meta-synthesis method, in January 2004, the first integrated version of the bankcard information exchange system was released. The system prototype is shown below (Figure 4).

\subsection{Overall quantitative conclusion}

According to the Emerging principles, unexpected situations are to be anticipated after the completion of the system prototype, some of which are beneficial while the rest are damaging. New problems, objectives, hypothesis, methods, outcomes constantly emerge. The new emergence requires constant validation, correction, loop iteration and gradual modification to the complex prototype system in order to enhance and improve the system. Dynamic adjustments are made to ultimately meet the engineering objectives (Sheng, 2009).

Milestones of the bankcard information system validation iteration are listed below:

(1) System launch. On 31st August, 2004, the new system was put into operation to replace the original system

(2) Pilot operation: The pilot operation lasted from September to November for three months and realized stable and reliable operation.

(3) Switchover: the switchover period lasted one year beginning from Shanghai Branch on 29th November, 2004 and ending on 8th November, 2005with Wuhan Branch, marking the completion of switchover to the centralized system of 18 branches. This signified the realization of centralized exchange and unified clearing and settlement
As a paradigm of the complex and giant system engineering, the bankcard information exchange system project renders distinct features in terms of the expert structure, machinery system and knowledge structure construction.

A. Expert structure

Based on engineering practices, UnionPay created a four-level expert structure which consists, from top down, of decision making, professional support, implementation, and sub project teams (Figure 5). During the metasynthesizing process guided by man-machine integration and man-centered principle, the expert structure exerts significant influence on the process.

B. Machinery system

Traditionally in the complex engineering such as infrastructure construction projects, the machinery system serves as the simulation tool in the man-machine integration. The system validates the experts' conception and instinct and offers guidance to the engineering management and implementation. In the giant and complex financial information system engineering, besides demonstrating the property of tool, the machinery system is embodied more in the primary engineering target, hence its importance is more outstanding. Compared with traditional giant and complex engineering, the machinery system in the giant and complex financial information system engineering are more complicated. It is further divided into multiple levels, including engineering management system, research and development system, testing system, production system.

C. Knowledge system

The giant and complex financial information system

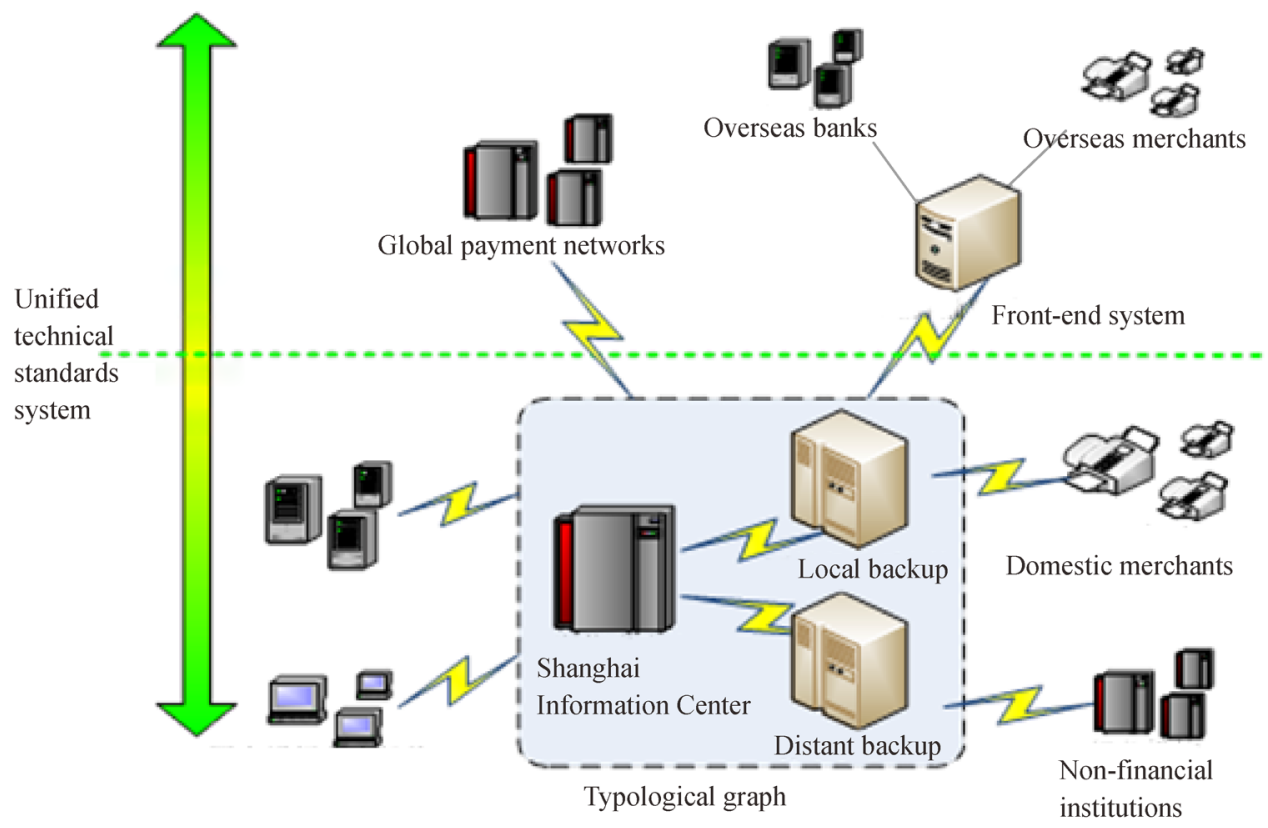

Figure 4. Prototype for bank card information system. 


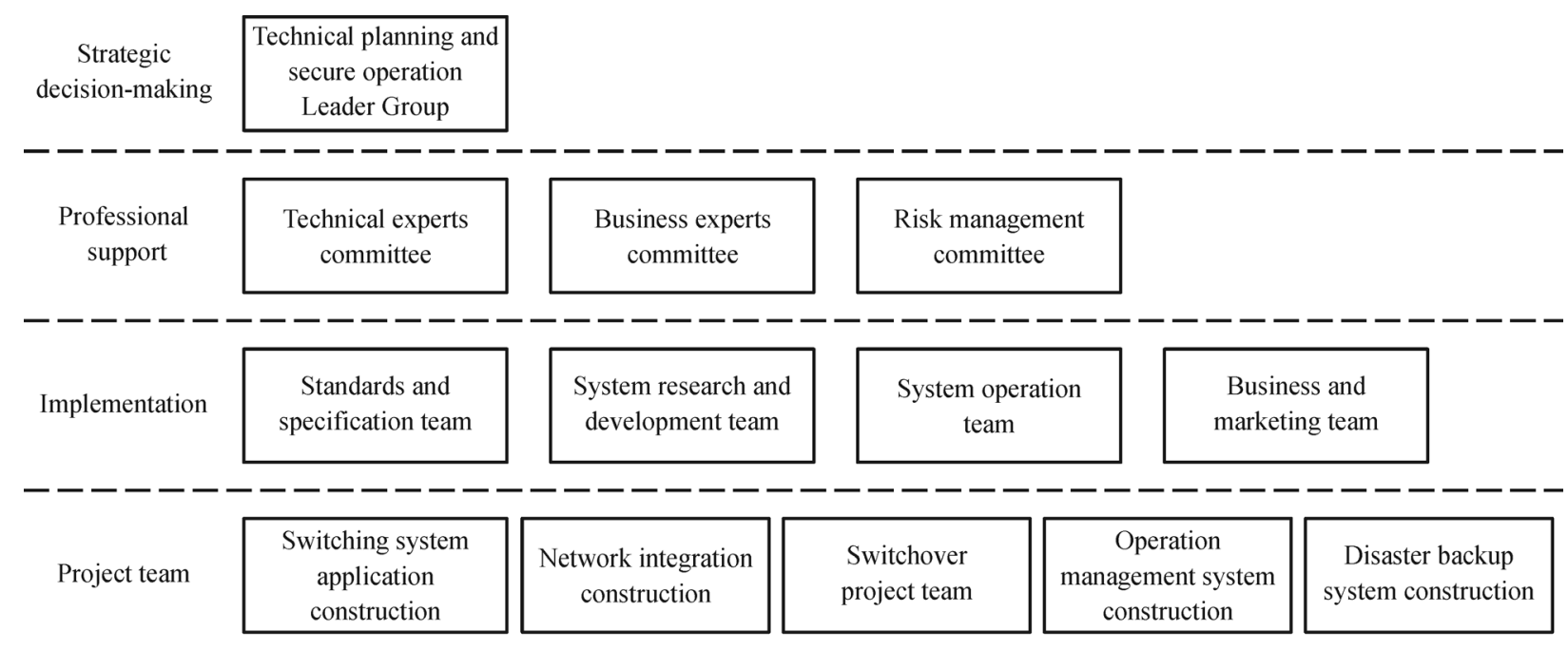

Figure 5. Engineering expert structure.

engineering owns a professional, cutting-edge, secure and regulated knowledge system.

- Professional refers to the fact that the knowledge system in the financial area is wide in range and deals with complicated and difficult business.

- Cutting-edge means that advanced information technologies and devices are often first implemented on a large scale in the financial system.

- Security is the basic requirement of financial transactions. Important financial information systems are required to pass Information Security Protection Level three or even Level four Test as well as ISO 27001.

- Being well-regulated is an important requirement of the financial information system engineering. The standard and rule must comply with national and industrial requirements. The research and development system follow CMMI requirements. The operation system complies with ITIL requirements (He, Wang, M., \& Wang, Q., 2013).

\section{Methods and tools of the giant and complex financial information system engi- neering management}

The giant and complex financial information system engineering covers both engineering lifecycle management and professional management. The former includes design, development, operation and enhancement. The latter typically includes standards and specification, risk management, intellectual properties. The management of each area in the giant and complex financial information system engineering is based on specific industrial best practices and holds typical methods and ideas as well as support toolkit (Figure 6).
4.1 Requirement management-Requirement management method for complex system

The internal and external requirement of a largely complex system often presents great complexity, i.e., it's systematic, international, dynamic, correlative and economic. Therefore all elements of each system should be considered as a whole and the relation of the system and its environment should be analyzed on higher level. Practical experience, theoretical knowledge and statistical data should be combined with computer technology. Mathematical model and simulation system should be established through expert seminars, empirical research and empirical judgment. Meanwhile, a conclusion and solution should be reached based on large-scale prototype verification, expert discussion and computer simulation. The process ensures that the requirement is correct, accurate and implementable. By building requirement management software and maintaining requirement traceability matrix, a well-regulated, flexible and dynamic requirement change process can be established so as to improve the proactivity and adaptability in the face of complex environmental changes.

\subsection{System design-Top-level design method}

The modeling and design of the giant and complex financial information system engineering has to take into consideration each level and factor of the project. The system should be viewed from an overall perspective. And the solution should be sought on the highest level (Wang, J., \& Di, Z., 2013). Regarding the bankcard information exchange system, a typical reference practice is elaborated as follows. The top level considerations are strategic planning, standards and specifications devel- 


\begin{tabular}{|c|c|c|c|c|c|}
\hline \multicolumn{6}{|c|}{ Lifecycle management } \\
\hline Domain & 1. Requirement & 2. Design & 3. Development & 4. Operation & 5. Optimization \\
\hline Method & $\begin{array}{l}\text { Complex system } \\
\text { requirement } \\
\text { management }\end{array}$ & Top level design & $\begin{array}{l}\text { Quantitative } \\
\text { developmen } \\
\text { management }\end{array}$ & $\begin{array}{l}\text { Integration } \\
\text { operation method }\end{array}$ & $\begin{array}{l}\text { Continuous } \\
\text { optimization }\end{array}$ \\
\hline \multirow{4}{*}{ Tool } & $\begin{array}{l}\text { Comprehensive } \\
\text { requirement } \\
\text { analysis method }\end{array}$ & Best practice & CMMI process & $\begin{array}{l}\text { Integration } \\
\text { operation model }\end{array}$ & Lean management \\
\hline & $\begin{array}{l}\text { Requirement } \\
\text { traceability matrix }\end{array}$ & $\begin{array}{l}\text { Top level design } \\
\text { model }\end{array}$ & Agile model & ITIL framework & 6 Sigma toolkit \\
\hline & $\begin{array}{l}\text { Requirement } \\
\text { change process }\end{array}$ & & PMI & $\begin{array}{l}\text { Service level } \\
\text { agreement }\end{array}$ & \\
\hline & & & & Evaluation method & \\
\hline \multicolumn{6}{|c|}{ Professional management } \\
\hline Domain & 6. Standards & 7. Risk & 8. Patent & 9. Innovation & 10. Industry \\
\hline Method & Standards system & $\begin{array}{l}\text { Risk management } \\
\text { system }\end{array}$ & $\begin{array}{l}\text { Intellectual } \\
\text { property } \\
\text { management }\end{array}$ & $\begin{array}{l}\text { Innovation } \\
\text { management } \\
\text { system }\end{array}$ & $\begin{array}{l}\text { Collaborative } \\
\text { development } \\
\text { method }\end{array}$ \\
\hline \multirow{4}{*}{ Tool } & $\begin{array}{l}\text { Standards and } \\
\text { specifications }\end{array}$ & $\begin{array}{l}\text { Laws and } \\
\text { regulations }\end{array}$ & IP strategy & $\begin{array}{l}\text { Dual drive } \\
\text { mechanism }\end{array}$ & 2 balance strategy \\
\hline & $\begin{array}{l}\text { Testing and } \\
\text { certification }\end{array}$ & $\begin{array}{l}\text { Risk management } \\
\text { requirements }\end{array}$ & Patent portfolio & $\begin{array}{l}2 \text { extremes on } 2 \\
\text { sides method }\end{array}$ & $\begin{array}{l}\text { Dual pattern } \\
\text { R\&D method }\end{array}$ \\
\hline & $\begin{array}{l}\text { Standards } \\
\text { management } \\
\text { method }\end{array}$ & $\begin{array}{l}\text { Joint risk } \\
\text { management } \\
\text { mechanism }\end{array}$ & Patent association & & $\begin{array}{l}\text { Dual effect } \\
\text { evaluation method }\end{array}$ \\
\hline & & $\begin{array}{l}\text { Technical } \\
\text { monitoring } \\
\text { platform }\end{array}$ & & & \\
\hline
\end{tabular}

Figure 6. Methods and tools of the complex financial information system engineering management.

opment, business and functions coordination, technical framework and implementation, system security and risk prevention and control, system operation and maintenance. Function and performance, efficiency and security, compatibility and extendibility should also be taken into account. Meanwhile, it is equally important that the relationship between each factor should be well coordinated in order to strike a sound balance within the entire system (Figure 7).

4.3 System development-quantitative research and development management system

According to the software research and development engineering practice, together with engineering requirements and project practice, UnionPay is able to design and establish a system that covers system research and development, engineering test, project management, and quality control management and apply quantitative management to the research and development process. In the financial information system engineering, the Waterfall model and Iteration model are two typical system research and development lifecycle models. In addition, the widely employed CMMI (Capability Maturity Model Integration) flow system which is based on processes and standards,

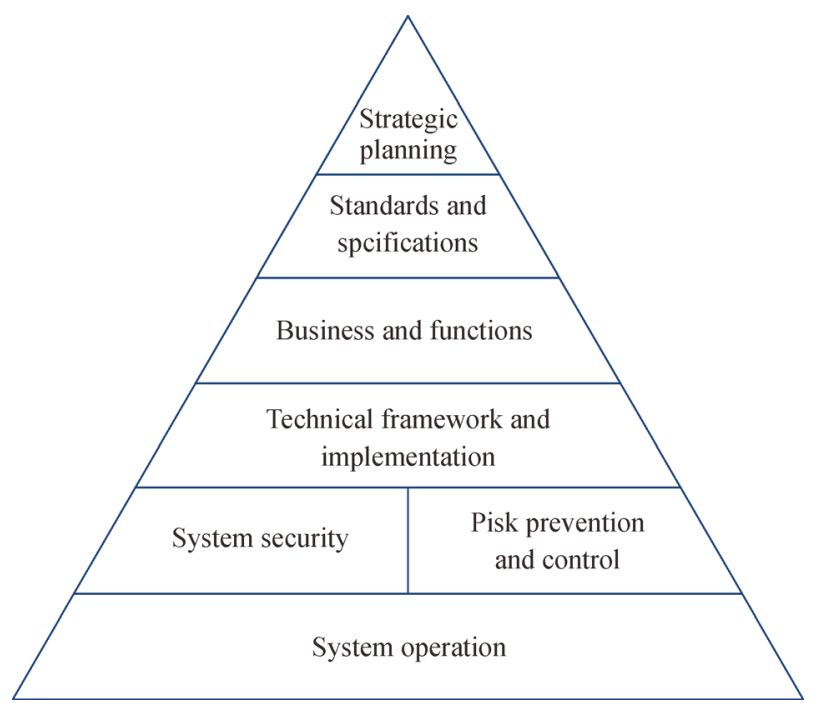

Figure 7. Reference implementation of top level design method.

as well as the Agile software development model based on iteration and efficiency, are all proved by practice to be effective research and development management methods. 
4.4 System operation-integrated operation management system

Traditional system operation is machine-centered and is focused on ensuring the safe and stable running of the system. The bankcard information exchange system engineering practice has proposed and established an integrated operation system. The customer-centered system upgrades traditional machine maintenance to platform operation characterized by directory structure, standardization, end-to-end process and customer-oriented practice. The core of the integrated operation management is to set out from the customer's perspective, establish the service contents, process and system, organizational structure, tool platform, quality monitoring and constant enhancement system and mechanism. Through quantitative methods such as SLA, outcome evaluation algorithm, the quantitative management can be applied to the entire process. In the giant and complex financial information system engineering, as a framework system is based on industrial best practice, ITIL (Information Technology Infrastructure Library) is able to be widely implemented. It applies IT service management business process to IT management to ensure the quality of the application provided to the end user.

\subsection{System optimization-continuous optimization method}

The giant and complex financial information system engineering is not a once-and-for-all task. Usually, it is constantly under enhancement. The complexity of the engineering is embodied in its proactivity and adaptability in the face of a complicated environment. In the first place, there is always the possibility that differences exist between the function implementation of each sub-system and original design. This requires changes of parameters, bug repairs and function refinement. Meanwhile, the complex engineering commonly lasts for a couple of years. The ever-changing environment asks for good self-enhancing and adapting ability. Otherwise, the originally advanced design might turns into a backward project upon implementation. In the bankcard information exchange system engineering, the team introduced Lean Six Sigma management system. By projectized method and quantifying tools, the team kept enhancing the engineering efforts.

4.6 Standards and specifications-industrial standards and testing and certification system

Financial service is regulated by strict industrial rules and specifications. The implementation of the financial information system engineering should take industrial standards and testing and certification system construction as a key task. The bankcard information exchange system engineering created 88 standards on national, industrial and corporate level, covering seven categories including foundational standard, exchange standard, acceptance standards, security standards etc..It also built China's bankcard industrial standards system with proprietary intellectual property rights. The engineering formulated a testing and certification system with 25 items in 3 categories. By maintaining strict technical standards in terms of security, function and quality, it ensured the implementation of the standards and specifications and created an agreeable ecosystem for the market.

\subsection{Risk management-risk prevention and control system}

Risk prevention and control is crucial for the financial information system. It should be established on the legal, institutional and technical level, accompanied by an integrated risk prevention and control system before, during, and after the incident. The bankcard information exchange system engineering implementation is demonstrated in the following aspects. It helped promote the launch of the Fifth Amendment to the Criminal Law, marking a milestone in strengthening the external legislative environment. It cooperated with both the public security institutions and member institutions to establish a joint prevention and control mechanism for crack down on bank card crime, improving the response speed to bankcard crime. It has created and launched more than 20 bankcard cross-industry business risk management rules which compose the institutional framework of bankcard risk joint prevention and control. It kept enhancing technical measures of risk prevention and control through cloud technology and big data risk control model research and development. It established the bankcard fraud detection service platform which has improved the risk prevention and control technology. According to Nelson Report, the bankcard fraud rate in China stands at $2.3 \%$, approximately one third that of the global average. Among them, credit card fraud rate is less than one tenth of the global average.

4.8 Intellectual property-the financial information industrial intellectual property management system

As China opens up, technical patents have become the most powerful weapon international companies could take advantage to check and balance the development of related industries in China. The current situation is that domestic financial information industry is lacking in overall planning and coordination of patent portfolio. The portfolio strategy where core IP interacts with peripheral IP is yet to be formulated. Hence it is challenging for a company to deal with global patent lawsuits on its own. The bankcard information exchange system engineering implementation has made the following efforts to enhance the intellectual property management system. First, it proposed the bankcard industry's IP strategy where patent application 
should be filed for technology, the patented technologies should be standardized and then the standards should be globalized, so as to promote management in an international context. Secondly, it changed the IP application strategy. It carried out the bankcard industry's strategic patent portfolio, turning from passive defense to proactive innovation. Thirdly, it made attempts to advocate the formation of industrial patent association, aiming at strengthening anti-risk capabilities for individual company. The association aims at dealing with lawsuits through industrial communication and cooperation and promoting industrial development. Through joint efforts to defend international IP charges, the association could pave the way for China's companies to the global arena.

\subsection{Innovation- forward-looking Innovation management system}

The financial information industry is in rapid development on innovative technology and business model, and therefore a forward-looking innovation management system should be established to keep self-improvement and development of the industry. Dual drive mechanism, i.e., market-driven and technology driven mechanism should be insisted. From market-driven perspective, the rapid transmission mechanism coping with market change and customer requirement change should be established, and innovation research topics should be gained from market investigation and customer feedback. From technologydriven perspective, product design should be driven by new technology in accordance with "two extremes" requirement, i.e., extreme experience on customer side and extreme security on platform side. The "very core" demand of customer experience should be made to perfection so as to constantly improve the product.

\subsection{Industry-Collaborative development method}

The core of collaborative development method is comprehensive application of policy, mechanism and evaluation. First, two balance policy is applied, i.e., the balance of industry investment and risk prevention, the balance of technical sophistication and market popularization. Second, dual pattern R\&D method is applied, i.e., independent $R \& D$ pattern in key technologies and joint $R \& D$ pattern in shared technologies. Finally, dual effect evaluation method is applied, i.e., effect evaluation on both enterprise competitiveness and industry collaborative development. Sustainable industry development should be established with collaborative development method so that the whole is greater in its effect than the parts aggregated.

\section{Conclusions}

As a paradigm of the giant and complex financial information system engineering, China Union Pay's bankcard information exchange system adopts the metasynthesis management methodology and the policy of overall optimization, reasonable hierarchy and orderly coordination. After undergoing three phases, namely, Centralized switching, Unified Clearing and Settlement, Model Platform, it realized the engineering objective of cross-bank and cross- border transaction processing as well as secure and reliable operation.

The testing result shows that an individual processing center could handle over 12,000 transactions per second at peak time, surpassing all other similar systems worldwide. Switching transaction reliability index hits $99.99 \%$. The system security level reaches (Ministry of Public Security) Level Four, the highest for commercial system. In 2014, it was awarded the second prize of the National Science and Technology Award and in 2007, special award of the Technology Development by People's Bank of China. The comment on its technical achievement is that the system reaches international advanced level. It leads the world in terms of transaction processing capability.

From the perspective of implementation, the total number of card issued reaches 5 billion, ranking the first worldwide. In 2015, cross-bank transaction volume hit 53.9 trillion CNY, surpassing major competitors, representing a 300 times increase from 2002. Bankcard penetration rate increased to $48 \%$, signifying that for every $100 \mathrm{CNY}$ consumption, $48 \mathrm{CNY}$ is paid with bankcards (China Union Pay, 2016).

The bankcard information technology service system has formed its own business model featuring commercial running, market promotion and large scale operation. It explored a holistic and coordinated development path for building a market-oriented, independently regulated, open and cooperative bankcard industry where standards are to be developed as a top priority. The system is among the first to introduce China's modern service to the world and achieved international operation. With the system in place, it took only 12 years for China to centralize the originally distributed resources in the bankcard industry, skipping the phase of payments with personal check where developed countries have experienced.

\section{References}

China Union Pay. (2016). Union Pay cross-bank transaction volume hit 53.9 trillion Yuan in 2015. Retrieved from http://corporate.unionpay. com/infonewsCenter/infoCompanyNews/file_126304454. html

He, J., Wang, M., \& Wang, Q. (2013). Status quo and development of China's engineering management (pp.73-88). Beijing: Higher Education Press.

Qian, X., Yu, J., \& Dai, R. (1990). A new discipline of science-the study of open complex giant system and its methodology. Nature Magazine, 
$13,3-10$.

Sheng, Z. (2009). Attempted study on the meta-synthesis of the giant and complex engineering-theoretical thinking on the engineering management of Sutong Bridge. Construction (Arlington), 05, 20-22.
Wang, J., \& Di, Z. (2013). The nature, logic and method of top level design. Reform, 08, 139-146.

Wang, Z. (2015). System engineering (pp. 235-251). Beijing: Peking University Press. 